\title{
Neuroplasticity of the Hypothalamic-Pituitary-Adrenal Axis Early in Life Requires Recurrent Recruitment of Stress-Regulating Brain Regions
}

\author{
Kristina A. Fenoglio, ${ }^{1}$ Yuncai Chen, ${ }^{2}$ and Tallie Z. Baram ${ }^{1,2}$ \\ Departments of ${ }^{1}$ Anatomy/Neurobiology and ${ }^{2}$ Pediatrics, University of California at Irvine, Irvine, California 92697-4475
}

\begin{abstract}
An eloquent example of experience-induced neuroplasticity involves the enduring effects of daily "handling" of rat pups on the expression of genes regulating hormonal and behavioral responses to stress. Handling-evoked augmentation of maternal care of pups induces long-lasting reduction of hypothalamic corticotropin releasing hormone $(\mathrm{CRH})$ expression and upregulates hippocampal glucocorticoid receptor levels. These changes promote a lifelong attenuation of hormonal stress responses. We have found previously that handlingevoked downregulation of CRH expression occurs already by postnatal day 9 , implicating it as an early step in this experience-induced neuroplasticity. Here, we investigated the neuronal pathways and cellular mechanisms involved. CRH mRNA expression in hypothalamic paraventricular nucleus (PVN) diminished after daily handling but not after handling once only, indicating that "recurrent" handling was required for this effect. Return of handled pups to their cage provoked a burst of nurturing behavior in dams that, in turn, induced transient, coordinate Fos expression in selected regions of the pups' brains. These included central nucleus of the amygdala (ACe) and bed nucleus of the stria terminals (BnST), regions that are afferent to PVN and influence CRH expression there. Whereas handling once sufficed to evoke Fos expression within ACe and BnST, expression in thalamic paraventricular nucleus, a region involved in storing and processing stress-related experience, required recurrent handling. Fos induction in all three regions elicited reduced transcription factor phosphorylation, followed by attenuated activation of $\mathrm{CRH}$ gene transcription within the PVN. These studies provide a neurobiological foundation for the profound neuroplasticity of stress-related genes evoked by early-life experience.
\end{abstract}

Key words: corticotropin releasing hormone; stress; handling; maternal care; thalamic paraventricular nucleus; amygdala

\section{Introduction}

Early-life experience induces enduring neuroplasticity of the hypothalamic-pituitary-adrenal (HPA) axis (Levine, 1967; Francis et al., 1999; Sanchez et al., 2001; Avishai-Eliner et al., 2002; Plotsky et al., 2005). Early studies found that adult rats exposed to brief, daily separations from the dam during the first weeks of life ("handled") have diminished adrenocortical responses to stress (Levine, 1957). Subsequent research demonstrated that early-life handling alters basal expression of neuronal genes involved in regulating neuroendocrine and behavioral responses to stress: reduced synthesis and stress-induced release of corticotropin releasing hormone $(\mathrm{CRH})$ from hypothalamus (Plotsky and Meaney, 1993) elicits attenuated hormonal stress responses in handled adult rats. Additionally, handling-evoked increased expression and binding of hippocampal glucocorticoid receptors (GR) may facilitate HPA axis negative feedback in adult handled rats (Plotsky and Meaney, 1993; Plotsky et al., 2005). These data

Received Sept. 26, 2005; revised Jan. 18, 2006; accepted Jan. 21, 2006.

This work was supported by National Institutes of Health Grants NS39307/MH73136, NS28912, and NS07444. We thank Dr. R. A. Bender for critical comments, B. Kapadia for technical support, and M. Hinojosa for editorial assistance.

Correspondence should be addressed to Dr. Tallie Z. Baram, Medical Sciences I, Zot 4475, University of California at Irvine, Irvine, CA 92697-4475. E-mail: tallie@uci.edu.

D01:10.1523/JNEUROSCI.4080-05.2006

Copyright $\odot 2006$ Society for Neuroscience $\quad 0270-6474 / 06 / 262434-09 \$ 15.00 / 0$ indicate that the handling procedure leads to enduring neuroplasticity of the system that governs processing of stress-related information and responses to stress.

The study of mechanisms for these long-lasting, handlingevoked changes benefited from two important breakthroughs. The first is the establishment of the mother-pup interaction as a key regulator of HPA axis neuroplasticity during the first postnatal weeks (Denenberg and Whimby, 1963; Levine, 1967; AvishaiEliner et al., 1995; Eghbal-Ahmadi et al., 1999; van Oers et al., 1999; Sanchez et al., 2001). Handling enhances this interaction by provoking maternal sensory stimulation of pups immediately after their return to the home cage (Brown et al., 1977). Enhanced maternal care, attributable to either natural variation (Liu et al., 1997; Caldji et al., 1998) or induced experimentally by handling (Plotsky and Meaney, 1993), has been shown to lower CRH expression in hypothalamic paraventricular nucleus (PVN), reduce hormonal responses to stress, and increase hippocampal GR levels (Avishai-Eliner et al., 2001), changes collectively termed "reduced HPA axis tone."

The second significant observation established that handlingevoked enduring changes do not develop together but arise sequentially (Avishai-Eliner et al., 2001). Persistent reduction of basal CRH expression in PVN occurs already by postnatal day 9 (P9), whereas diminished stress-induced ACTH and corticosterone release emerges by P23 and increased hippocampal GR ex- 
pression is evident by P45. Reduced PVN-CRH expression already by $\mathrm{P} 9$ supports a role for this gene regulation in the molecular cascades bridging handling-evoked maternal care and long-term neuroplasticity of the HPA axis. Therefore, it is reasonable to assume that sensory input from the mother is conveyed via specific neuronal pathways to $\mathrm{CRH}$-expressing cells within pups' PVN (Eghbal-Ahmadi et al., 1999). Such functional pathways (Eghbal-Ahmadi et al., 1999; Sanchez et al., 2001; Herman et al., 2003) include neurons within thalamic paraventricular nucleus (PVT), central amygdala (ACe), and bed nucleus of stria terminalis (BnST). Here, we tested the hypotheses that (1) an early phase of HPA axis neuroplasticity evoked by handling involves coordinate, transient activation of regions that link maternal sensory stimulation to CRH neurons in PVN, and (2) "recurrent" handling is required to "store" (in one or more of these intermediary regions) the memory of this experience and initiate enduring neuroplastic changes in $\mathrm{PVN}-\mathrm{CRH}$-expressing neurons.

\section{Materials and Methods}

Animals. Timed-pregnant Sprague Dawley female rats were housed in an uncrowded, quiet animal facility room on a $12 \mathrm{~h}$ light/dark cycle and were provided with food and water ad libitum. Parturition was checked daily, and the day of birth was considered P0. On P1, litters were mixed and adjusted to establish similar numbers of males and females. Complete litters were randomly assigned to one of the following early-life rearing conditions: handled daily from P2 to P8 or P9 (see below); handled once, on $\mathrm{P} 5, \mathrm{P} 8$, or $\mathrm{P} 9$; undisturbed during $\mathrm{P} 2-\mathrm{P} 9$; or undisturbed and deprived of maternal care for $3 \mathrm{~h}$ on P9. These studies used 132 male pups. All experiments were approved by the University Animal Care Committee and conformed to National Institutes of Health guidelines.

Handling and maternal observation. The daily handling procedure was modified from that originally described by Levine (1957), as described previously (Avishai-Eliner et al. 2001; Fenoglio et al., 2004; Fenoglio et al., 2005). Cages were brought into the laboratory daily at 8:30 A.M. (Watts et al., 2004). The dam and pups were placed into separate bedded cages (pups were kept euthermic via a heating pad located underneath the cage). After $15 \mathrm{~min}$, pups were placed back into their home cage, followed by the dam, and returned to the vivarium. Undisturbed litters remained in the vivarium from $\mathrm{P} 2$ to $\mathrm{P} 9$. For all experimental groups, cage changing did not occur during this time. Every day, after handled pups were reunited with the dam and returned to the vivarium, maternal behavior (specifically licking and grooming) was observed using a protocol modified from Liu et al. (1997) as used by Brunson et al. (2005). Each maternal observation session consisted of 123 min epochs. Within each epoch, the duration of licking and grooming of pups was recorded during the first $2 \mathrm{~min}$, and the total amount of time spent licking and grooming was scored per session. Maternal behavior was also determined in undisturbed litters and in those handled once on P5 or P8 (on the day of handling).

Immunocytochemistry studies. Fos protein and phosphorylated extracellular-signal regulated kinase (pERK) were examined in rats handled daily and killed at different time points (at 5, 30, 60, 90, or $120 \mathrm{~min}$ ) after their return to the dam on $\mathrm{P} 9$ compared with several control groups. These included pups handled once on P9 and killed at the same time points, the undisturbed group, and pups deprived from the mother for $3 \mathrm{~h}$ and not returned to the cage. Rats were anesthetized with sodium pentobarbital $(100 \mathrm{mg} / \mathrm{kg}$, i.p.) and then perfused through the ascending aorta with $0.9 \%$ saline solution, followed by freshly prepared, cold $4 \%$ paraformaldehyde in $0.1 \mathrm{M}$ sodium phosphate buffer (PB), pH 7.4. Brains were removed and postfixed overnight, cryoprotected in 15 and $30 \%$ sucrose $/ \mathrm{PB}$ solutions, and stored at $-80^{\circ} \mathrm{C}$. Brains were sectioned at 35 $\mu \mathrm{m}$ using a cryostat, and sections were collected in tissue-culture wells containing $0.1 \mathrm{M}$ PB.

For neuroanatomic orientation, one in every six sections were stained with toluidine Nissl stain. Adjacent series at the levels of the anterodorsal (AD) BnST (4.7 mm, anterior to the interaural line), ACe (3.8-2.9 mm), and PVT $(2.9-2.0 \mathrm{~mm})$ were processed for Fos immunoreactivity (IR)

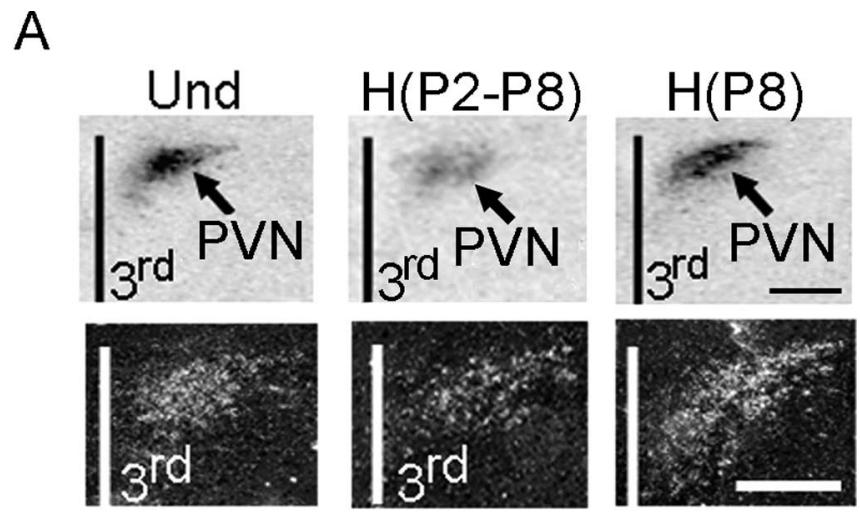

B

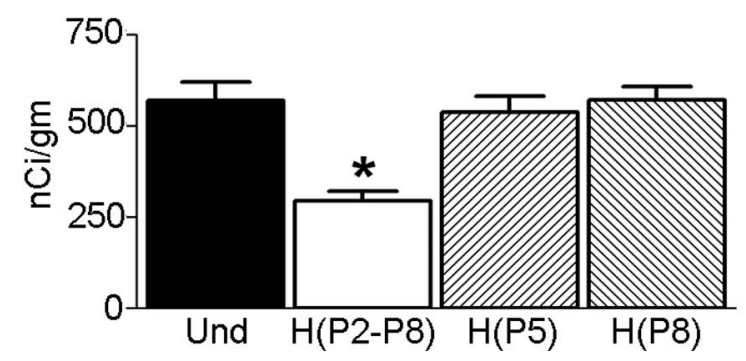

Figure 1. CRH mRNA expression is reduced in PVN of rats handled recurrently (from $\mathrm{P2}-\mathrm{P} 8$ ) but not in those handled once. $A$, Bright-field and dark-field photomicrographs of coronal sections at the level of the PVN that were subjected to in situ hybridization for CRH mRNA and then emulsed. B, Quantitative analysis of CRH signal over PVN. Basal levels of CRH expression were reduced by $52 \%$ in P9 rats handled daily on P2-P8 compared with those of pups left undisturbed (Und). Handling once was insufficient to induce changes in gene expression: CRH mRNA levels in PVN of $P 9$ rats handled once, either on $P 5$ or on $P 8$, did not differ from those of undisturbed controls ( $p=0.64$ and 0.99 , respectively). H(P2-P8), Handled daily from P2 to P8; $H(P 5)$, handled once on $P 5 ; H(P 8)$, handled once on P8. Vertical line labeled "3rd" indicates the third ventricle. Scale bars, $500 \mu \mathrm{m} .{ }^{*} p<0.001$, values are significantly different from undisturbed. $n=6-7$ brains per group.

(Sherwood and Timiras, 1970). The coordinates for the regions examined were derived to compare with the corresponding structures in adult rats (Paxinos and Watson, 1982): BnST (Ju et al., 1989; Herman et al., 1994), ACe (Prewitt and Herman et al., 1994), PVT (Bhatnagar and Dallman, 1998) as shown in Figure 4. Series of sections at the level of the PVN $(3.8-3.5 \mathrm{~mm})$ were processed for pERK-IR.

Free-floating sections were subjected to the standard avidin-biotin complex (ABC) methods as described previously (Chen et al., 2000, 2001a). Briefly, after three washes with $0.01 \mathrm{M}$ PBS containing $0.3 \%$ Triton X-100, $\mathrm{pH} 7.4$ (PBS-T), sections were treated with $0.3 \% \mathrm{H}_{2} \mathrm{O}_{2}$ in PBS for $30 \mathrm{~min}$. Nonspecific binding was blocked with $10 \%$ normal goat serum in PBS-T for 30 min. PVT, ACe, and BnST sections were incubated with polyclonal Fos antibody (1:20,000; Oncogene Sciences, Cambridge, $\mathrm{MA}$ ) in PBS for $24 \mathrm{~h}$. PVN sections were incubated with polyclonal pERK antibody (1:400; Sigma, St. Louis, MO) in PBS for $72 \mathrm{~h}$ at $4^{\circ} \mathrm{C}$. Subsequently, sections were washed in PBS-T (three times for $5 \mathrm{~min}$ ) and incubated in biotinylated goat anti-rabbit IgG (1:400; Vector Laboratories, Burlingame, CA) in PBS for $2 \mathrm{~h}$. After washing in PBS-T, sections were incubated in $\mathrm{ABC}$ solution (1:100; Vector Laboratories) for $3 \mathrm{~h}$ and rinsed in three $5 \mathrm{~min}$ PBS-T washes. The reaction product was visualized by incubating sections for $8-10 \mathrm{~min}$ in $0.04 \% 3,3^{\prime}$-diaminobenzidine containing $0.01 \% \mathrm{H}_{2} \mathrm{O}_{2}$. The specificity of the primary antisera was tested by preadsorbing the antiserum overnight with purified Fos or pERK blocking peptide $(100 \mu \mathrm{g} / \mathrm{ml})$. The specificity of the secondary antibody was tested by omitting the primary antiserum during the first incubation. There were no immunoreactive cells in sections subjected to these testing conditions.

In situ hybridization histochemistry studies. Basal levels of CRH mRNA 
A

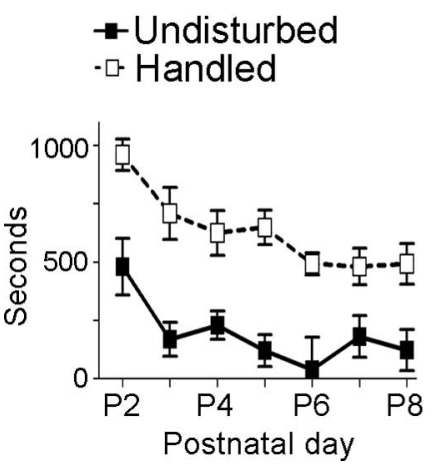

B

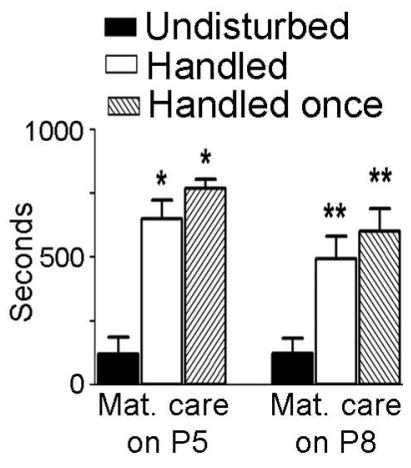

Figure 2. Sensory stimulation of pups by the dam is enhanced every day after handled pups are returned to the cage. $A$, Maternal care, specifically licking and grooming, was observed and quantified daily during P2-P8. The duration of maternal licking and grooming (during the 30 min after handled pups were returned to their dam) was twofold higher than that of undisturbed dams at the same time of day (paired $t$ test, $p<0.001 ; R^{2}=0.97$ ). $\boldsymbol{B}$, This increase of licking and grooming of pups occurred even when handling was performed once only on P5 or on P8. Mat. care, Maternal care. * indicates that values differ significantly from those of P5 undisturbed litters; ${ }^{* *}$ indicates that values are significantly different from those of P8 undisturbed litters; $p<0.05 . n=5$ litters per group.

were investigated in PVN of $\mathrm{P} 9$ pups that were handled daily from $\mathrm{P} 2$ to P8, handled once on P5 or P8, or remained undisturbed. [Note that previous studies have shown that handling from P2 to P8 is sufficient to induce long-term neuroendocrine changes (Avishai-Eliner et al., 2001; Fenoglio et al., 2005). Here, handling-induced changes of basal CRH mRNA expression were examined in pups handled from P2 to P8 and killed $24 \mathrm{~h}$ after the last day of handling, on P9.]

Levels of unedited, heteronuclear CRH RNA were determined as a measure of direct activation of CRH gene expression. Differential activation of the CRH gene on P9 was compared between pups that were handled (from P2 to P8) and those that were undisturbed during these days. On P9, both groups were subjected to the handling procedure (i.e., were separated from the dam for $15 \mathrm{~min}$ and then returned to the dam). CRH hnRNA was measured at the onset of this separation (basal), at the moment of the pups' return (15 min from separation onset), as well as at 45 and 75 min after the onset of separation from the mother (i.e., 30 and $60 \mathrm{~min}$, respectively, after the pups' return to the dam). For all in situ hybridization histochemistry (ISH) studies, rats were killed by rapid decapitation, and brains were quickly removed and frozen on dry ice.

Expression levels of CRH mRNA and heteronuclear RNA (hnRNA) in PVN were determined using previously described ISH methods (Yi and Baram, 1994; Avishai-Eliner et al., 2001; Chen et al., 2001b). Coronal sections $(20 \mu \mathrm{m})$ were collected on gelatin-coated slides and stored at $-80^{\circ} \mathrm{C}$. Sections were air dried and postfixed in $4 \%$ paraformaldehyde in PB for $20 \mathrm{~min}$. Sections underwent a series of dehydration and rehydration steps through graded ethanol washes and were exposed to $0.25 \%$ acetic anhydride in $0.1 \mathrm{~m}$ triethanolamine, $\mathrm{pH} 8$, for $8 \mathrm{~min}$. After dehydration through graded ethanol washes, sections were incubated with prehybridization buffer for $1 \mathrm{~h}$ in a humidified chamber (at $42^{\circ} \mathrm{C}$ for mRNA and $55^{\circ} \mathrm{C}$ for heteronuclear RNA). Levels of mature CRH mRNA were examined using $0.25 \times$ $10^{6} \mathrm{cpm}$ of ${ }^{35} \mathrm{~S}$-labeled deoxyribonucleotide probe. Sections were hybridized with probe overnight at $42^{\circ} \mathrm{C}$. Sections were washed at $55^{\circ} \mathrm{C}$ in $2 \times$ and $1 \times$ SSC for 5 min each and then successively in four fresh solutions of $0.3 \times$ SSC for 15 min each (note that $1 \times$ SSC denotes $0.15 \mathrm{M} \mathrm{NaCl}, 15 \mathrm{~mm}$ trisodium citrate buffer, $\mathrm{pH}$ 7.0). In the second set of experiments, levels of unedited CRH heteronuclear RNA were determined using $1 \times 10^{6} \mathrm{cpm}$ of ${ }^{35}$ S-labeled ribonucleotide probe [courtesy of Drs. S. J. Watson (University of Michigan, Ann Arbor, MI) and S. Rivest (CHUL Research Center, Quebec, Canada)]. Sections were hybridized with probe overnight at $55^{\circ} \mathrm{C}$, then rinsed in $4 \times$ and $2 \times$ SSC, subjected to a $30 \mathrm{~min}$ RNase wash at $37^{\circ} \mathrm{C}$, followed by a series of washes at $55^{\circ} \mathrm{C}: 2 \times$ SSC $(5 \mathrm{~min}), 1 \times$ SSC $(30 \mathrm{~min})$, $0.25 \times$ SSC $(1 \mathrm{~h})$, and $0.03 \times$ SSC for $30 \mathrm{~min}$. All sections were dehydrated in graded ethanol solutions containing $0.3 \mathrm{M}$ ammonium acetate, followed by
$100 \%$ ethanol. Sections were air dried and apposed to film (Kodak BioMax MR Film, MR-1; Eastman Kodak, Rochester, NY) for $\sim 10$ d. Selected sections were dipped in emulsion (NTB-2; Eastman Kodak) and developed after 3 weeks.

Semiquantitative analyses and statistical considerations. Initial experiments evaluated neuronal activation throughout a series of sections spanning the brain from the anteriormost border of the diagonal band of Broca $(6.2 \mathrm{~mm}$, anterior to the interaural line) to the bottom of the brainstem $(-4 \mathrm{~mm}$, posterior to the interaural line). Little constitutive or handling-induced expression of the cellular activation markers used here was noted in regions other than those discussed.

Section sampling and analyses were conducted without knowledge of treatment (Eghbal-Ahmadi et al., 1999; Brunson et al., 2001; Fenoglio et al., 2004). For an unbiased determination of cells labeled for Fos or pERK, a systematic random series of sections (one in two for BnST and PVN, one in three for ACe, and one in four for PVT) was selected for each animal. Cell nuclei were counted as described previously (Chen et al., 2001a, 2004; Bender et al., 2001) under $40 \times$ magnification in matching sections. The boundaries of each region of interest were delineated in adjacent sections labeled with methyl green Nissl stain. The average number of Fos-immunopositive cells was determined from three to five sections for PVT, three sections for ACe, and two sections for BnST. Cells positive for pERK were counted in two to four PVN sections, generating a mean number of immunoreactive cells per region for each brain. For the ISH studies, signal was analyzed on digitized films using the ImageTool software program (University of Texas Health Science Center, San Antonio, TX). The signal was analyzed in the linear range of optical densities as evaluated using ${ }^{14} \mathrm{C}$ standards. Means and SEs were calculated for each brain from two to four anatomically matched sections. For all studies, statistical significance $(p<0.05)$ among experimental groups was determined using one-factor ANOVA with Bonferroni's post hoc test (Prism; GraphPad, San Diego, CA) unless otherwise noted.

\section{Results}

\section{CRH expression in the PVN of P9 rats is modified after} recurrent daily handling but not after a single handling event As adults, rats handled daily during the first weeks of life (recurrent handling) express lower levels of $\mathrm{CRH}$ in the hypothalamic PVN compared with rats that have been raised undisturbed (Plotsky and Meaney, 1993; Avishai-Eliner et al., 2001). To study the mechanism that may underlie this form of developmental neuroplasticity, we first examined whether the recurrence of handling was required to induce this downregulation of hypothalamic CRH expression. Therefore, we compared CRH mRNA expression in PVN of $\mathrm{P} 9$ rats that were handled daily from $\mathrm{P} 2$ to P8 with that of rats handled only once (on either P5 or P8) and to undisturbed age-matched controls. Compared with undisturbed controls, CRH mRNA levels were significantly reduced in PVN of P9 rats that were handled daily from P2 to P8 ( $t$ test, $p<0.001$ ) (Fig. 1), consistent with our previous findings (Avishai-Eliner et al., 2001; Fenoglio et al., 2004). In contrast, CRH mRNA levels of $\mathrm{P} 9$ rats that were handled once only (on P5 or P8) did not differ from those of undisturbed pups (Fig. 1). These findings indicate that a single handling event does not suffice to evoke neuroplasticity of CRH expression and that the enduring downregulation of CRH expression (Plotsky et al., 1993; Fenoglio et al., 2005) requires recurrent handling during the first week of life.

\section{The handling procedure increases sensory stimulation of pups by the dam}

How does recurrent handling of rat pups influence the expression of stress-related genes, specifically hypothalamic CRH? Recurrent handling has been shown to enhance maternal nurturing behaviors, such as licking and grooming, toward the pups (Brown et al., 1977; Liu et al., 1997). Therefore, we tested the notion that returning the pups to their cage after handling elicits 


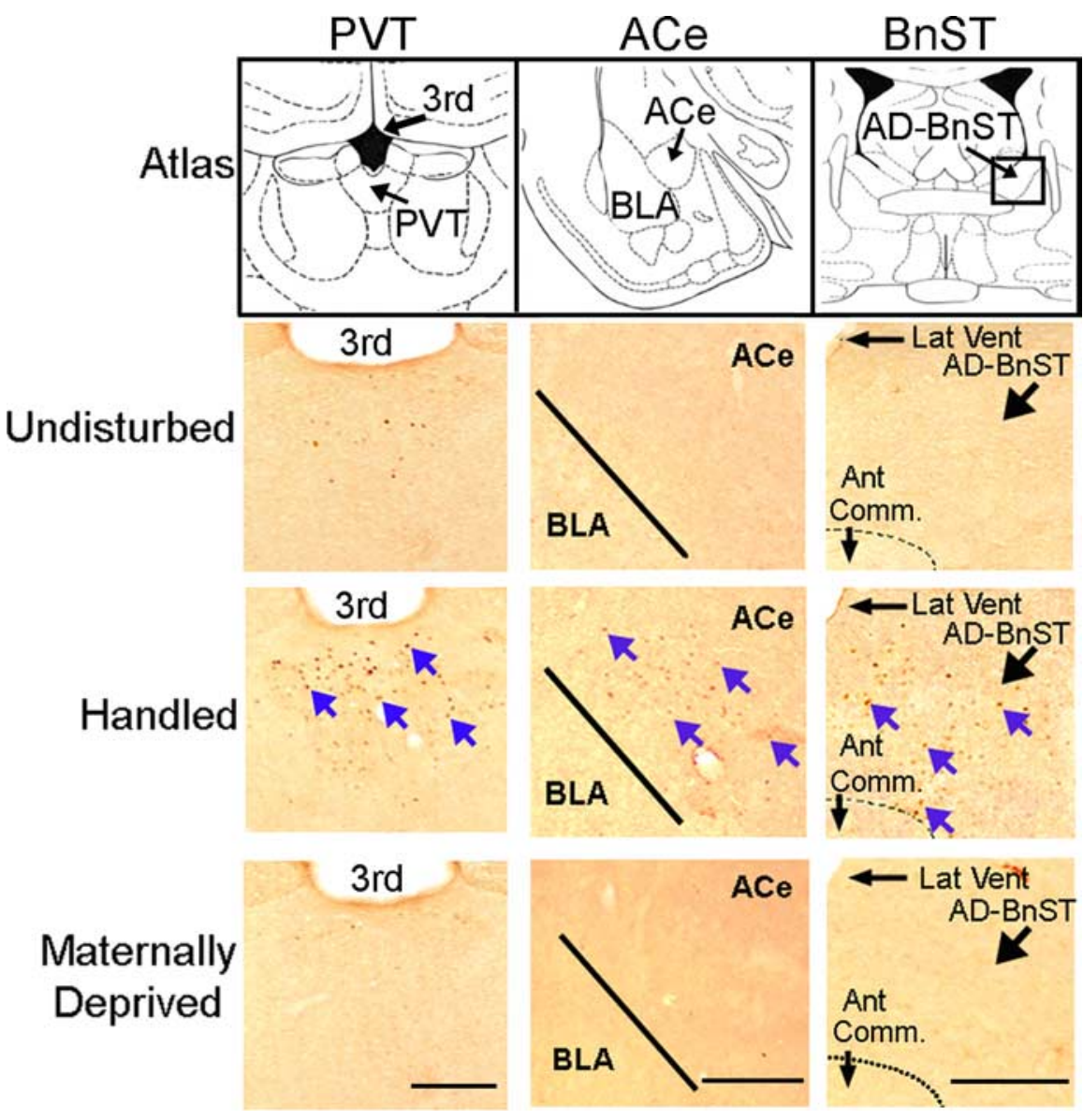

Figure 3. Fos-immunoreactive neurons are significantly increased in PVT, ACe, and BnST of P9 handled pups after their return to the dam. Bright-field photomicrographs of coronal brain sections of PVT (left column), ACe (middle column), and BnST (right column) at the levels indicated by the atlas images in the first row (Paxinos and Watson, 1982) are shown. Fos-positive cells were few in PVT and virtually absent in ACe and BnST of P9 pups that remained undisturbed during P2 to P9 (second row) or were deprived of maternal care for $3 \mathrm{~h}$ on $\mathrm{P9}$ (fourth row). In contrast, Fos-labeled cells (blue arrows) were abundant in PVT, ACe, and BnST of rats handled from $\mathrm{P} 2$ to $\mathrm{P} 9$ and perfused 30 min after their return to the dam (third row). Ant Comm, Anterior commissure; BLA, basolateral amygdala nucleus; Lat Vent, lateral ventricle; 3rd, third ventricle. Scale bars, $500 \mu \mathrm{m}$.

a "burst" of maternally derived sensory stimulation of the pups, which in turn, activates and modulates stress-regulating pathways within the pups' brains. Indeed, the return of handled pups to the dam rapidly elicited a barrage of maternally derived sensory stimulation (Fig. 2A). Specifically, maternal licking and grooming were increased twofold during the first $30 \mathrm{~min}$ after the pups' return to the dam. This significant burst of sensory stimulation of the pups occurred after each handling (Fig. 2A), including the single handling on $\mathrm{P} 5$ or on $\mathrm{P} 8$ (Fig. $2 \mathrm{~B}$ ). These data indicate that, although a single handling event elicits a burst of maternal stimulation, this single barrage of sensory input is not sufficient to influence hypothalamic $\mathrm{CRH}$ expression.

Sensory stimulation induced by the daily handling procedure activates brain structures that modulate stress-related gene expression

Maternal-derived sensory stimulation of the pups may be conveyed to $\mathrm{CRH}$-expressing neurons in the $\mathrm{PVN}$ via brainstem and limbic regions that are involved in integrating stress signals (van Oers et al., 1998; Eghbal-Ahmadi et al., 1999; Sanchez et al., 2001), including the PVT, ACe, and BnST (supplemental Fig. 1, available at www.jneurosci.org as supplemental material). This putative pathway requires that neurons within these regions be coordinately activated by the burst of maternal licking and grooming after pups are returned to the dam (Fig. 2). To investigate this possibility, we studied expression of the immediate-early gene c-fos in PVT, $\mathrm{ACe}$, and BnST. Fos protein is considered a useful, relatively quantitative marker of neuronal activity (Labiner et al., 1993; Martinez et al., 2002; Peng and Houser, 2005). In addition, several laboratories have demonstrated that the cellular machinery required to induce Fos is functional in the rat during the first week of life and is responsive to gentle physiological stimuli (Dent et al., 2000; Dube et al., 2000; Hatalski et al., 2000). Fos-IR was virtually absent throughout the brain in 9-d-old undisturbed pups, as well as in pups deprived from maternal care for $3 \mathrm{~h}$ on $\mathrm{P9}$ and not returned to the home cage (Fig. 3). In contrast, numerous Fos-expressing neurons were apparent in the PVT, ACe, and $\mathrm{AD}-\mathrm{BnST}$ of P9 pups that were handled daily on P2-P9 and killed 30 min after their return to the dam (Fig. 3).

To study whether activation of PVT, $\mathrm{ACe}$, and BnST was attributable specifically to the daily barrage of maternal stimulation of handled pups, we examined the time course of Fos expression in these regions. In PVT and BnST, the numbers of Fos-immunoreactive neurons were relatively low $5 \mathrm{~min}$ after the return of pups to the dam. They increased progressively, peaked at 30-60 min, and then declined sharply by $120 \mathrm{~min}$ (Fig. 4). This time course is consistent with the profile of Fos expression after tactile stimulation in adult rats (Bisler et al., 2002), and Fos expression has been demonstrated after anogenital stimulation of immature animals (Coolen et al., 1997; Caba et al., 2003). These facts support the notion that the burst of maternally derived sensory stimulation (Fig. 2) provoked Fos expression in PVT and BnST. In contrast, substantial numbers of Fos-expressing neurons were detectable in ACe already 5 min after the pups' return to the cage (Fig. 4). This suggests that Fos induction in ACe was initiated earlier, perhaps by the handling procedure itself.

\section{Fos induction in the pups' PVT requires recurrent bursts of handling-evoked sensory input from the mother}

Recurrent handling was required to downregulate CRH mRNA levels in PVN of P9 rats, because handling once was insufficient to reduce these levels (Fig. 1). This raised the hypothesis that, if activation of PVT, ACe, and/or BnST contributes to this downregulation, then recurrent handling should be required to activate one or more of these regions that may function as a "memory store" in which previous handling experiences were integrated. Therefore, we investigated whether single or recurrent handling was required to activate each of the regions discussed above by comparing the numbers of Fos-immunopositive neurons in rats handled daily with those in rats handled once.

As shown in Figure 5, a single handling event was sufficient to induce Fos expression in neurons of $\mathrm{ACe}$ and BnST. In contrast, a 
single handling event failed to induce Fos in PVT neurons: the number of Fos-positive cells in once-handled rats $(20.53 \pm 3.5)$ was indistinguishable from that in rats left undisturbed $(28.9 \pm 1.5)$, and both were significantly lower than the number of Fos-labeled neurons in PVT of rats handled daily (78.3 \pm 8.6; $\left.F_{(3,15)}=42.45 ; p<0.001\right)$. These data indicate that, unlike in ACe and BnST, activation of PVT neurons requires recurrent handling. Furthermore, selective activation of PVT neurons after recurrent (but not single) handling might alter their activity (firing rate, neurotransmitter release, etc.), providing differential, "memory-conveying" information to CRH-expressing neurons in PVN (supplemental Fig. 1, available at www. jneurosci.org as supplemental material). Indeed, PVT has been proposed previously as a region involved in processing the "memory" of experiences related to the stress-response system (Bhatnagar et al., 1998, 2000).

\section{Activation of a transcription factor regulating $\mathrm{CRH}$ gene expression is reduced in PVN of pups \\ handled recurrently}

The data shown above suggest that recurrent bursts of handling-evoked maternal sensory stimulation elicit a "signal" that, via intermediary structures including the PVT, eventually reaches PVN, in which it has the capacity to reduce $\mathrm{CRH}$ gene expression (supplemental Fig. 1, available at www.jneurosci.org as supplemental material). Bursts of maternal sensory stimulation can therefore be expected to alter the activation of transcription factors involved in the regulation of $\mathrm{CRH}$ expression in PVN. Phosphorylation of cAMP response element-binding protein (CREB) and ERK influence the initial activation of the critical CRE domain on the CRH gene promoter (Seasholtz et al., 1988). pERK, a component of the Ras-mitogen-activated protein kinase signaling cascade, is considered crucial for maintained phosphorylation of CREB beyond the first seconds after synaptic activation, contributing to plasticity at longer timescales (West et al., 2002). Both CREB and ERK are ubiquitously phosphorylated in PVN of undisturbed P9 rats (Fig. $6 \mathrm{~B})$ and are thus candidates for deactivation by inhibitory inputs evoked by handling.

In $\mathrm{P} 9$ rats, the number of pERKimmunoreactive cells was markedly reduced 30 min after recurrently handled pups were returned to the dam and remained depressed for at least $2 \mathrm{~h}$ (Fig. $6 \mathrm{~A}$ ). This reduction did not occur in pups handled once only, in which the number of pERKexpressing neurons was high and indistinguishable from that in undisturbed controls or in maternally deprived pups (Fig. 6B). Therefore, the downregulation of $\mathrm{pERK}$ required recurrent handling. The number of pCREB-expressing neurons was not

A

B
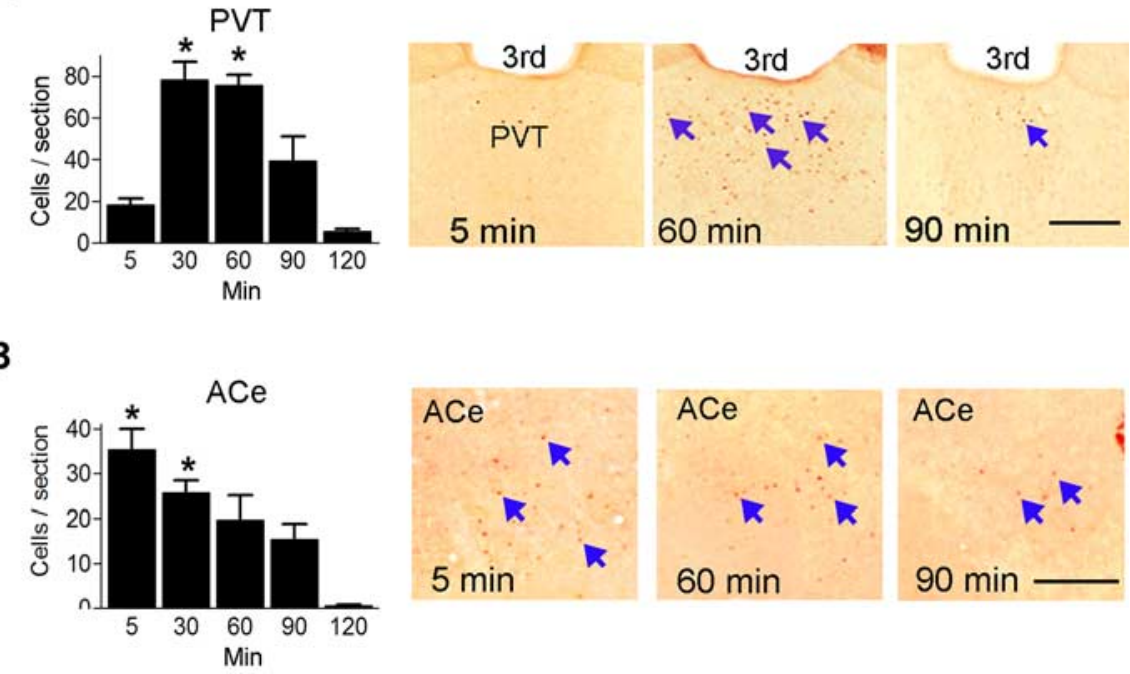

$\mathrm{ACe}$
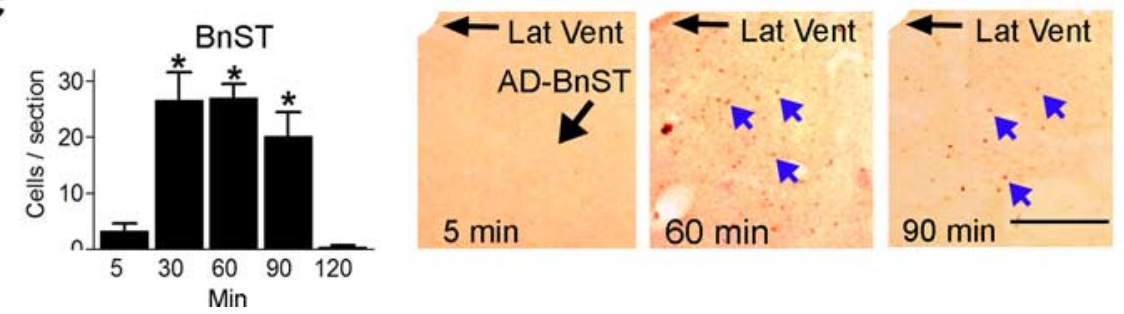

Figure 4. Time course of Fos expression in PVT, ACe, and BnST of daily handled pups after their return to the dam. Quantification and bright-field photomicrographs of Fos-labeled neurons (blue arrows) in PVT ( $\boldsymbol{A}), \mathrm{ACe}(\boldsymbol{B})$, and BnST ( $\boldsymbol{C}$ of pups handled recurrently (P2-P9) and perfused at 5, 30, 60, 90, or 120 min after their return to the dam on P9 are shown. $A$, Fos induction in PVT peaked $30-60 \mathrm{~min}$ after the pups' return to the dam and disappeared by $120 \mathrm{~min}$ (compared with $120 \mathrm{~min}, F_{(4,15)}=23.3 ; p<$ 0.005). $\boldsymbol{B}$, The number of Fos-immunoreactive neurons in ACe was maximal at 5 min and declined over the next $2 \mathrm{~h}\left(F_{(4,9)}=8.54\right.$; $p<0.01)$. C, Fos induction in BnST followed a time course similar to that in the PVT $\left(F_{(4,12)}=14.63 ; p<0.05\right)$. ACe, $n=3$ brains per time point; AD-BnST, $n=3-4$ brains per time point; PVT, $n=4-7$ brains per time point. Lat Vent, Lateral ventricles. Scale bars, $500 \mu \mathrm{m} .{ }^{*} p<0.05$, values statistically differ from those at $120 \mathrm{~min}$.

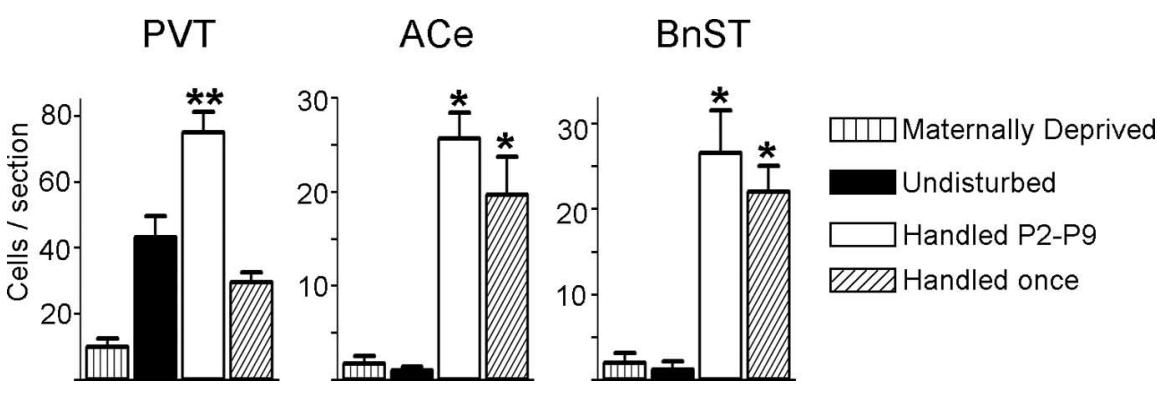

Figure 5. In PVT (unlike ACe and BnST), major Fos activation requires recurrent handling. The number of Fos-labeled cells in PVT, ACe, and BnST were compared in pups handled daily during P2-P9 (and perfused 30 min after their return to the dam on P9), handled once on $\mathrm{P9}$ (and perfused at the same time point), deprived of maternal care for $3 \mathrm{~h}$ on $\mathrm{P} 9$ (and not returned to the home cage; a "negative control" for maternal sensory input), or remaining undisturbed during P2-P9. The number of Fos-positive cells in PVT of pups handled once (bar with diagonal lines) was not different from that in undisturbed pups (black bar), whereas recurrent handling (white bar) caused a threefold increase in Fos-labeled cells $\left(F_{(3,16)}=20.87 ; p<0.01\right)$. In ACe and BnST, single and recurrent handling induced Fos expression to similar extents. ACe, $n=2-3$ brains per time point; $B n S T, n=2-3$ brains per time point; PVT, $n=3-4$ brains per time point. * indicates that values differ statistically from maternally deprived and undisturbed control groups; ${ }^{* *}$ indicates that values are significantly different from all other groups; $p<0.05$.

changed in any experimental group (data not shown). These data indicate that (1) the burst of handling-evoked maternal sensory stimulation elicits a signal that eventually reaches the PVN and that (2) the consequences of this signal are to reduce phosphorylation (activation) of a key regulatory factor of $\mathrm{CRH}$ gene transcription. 
A
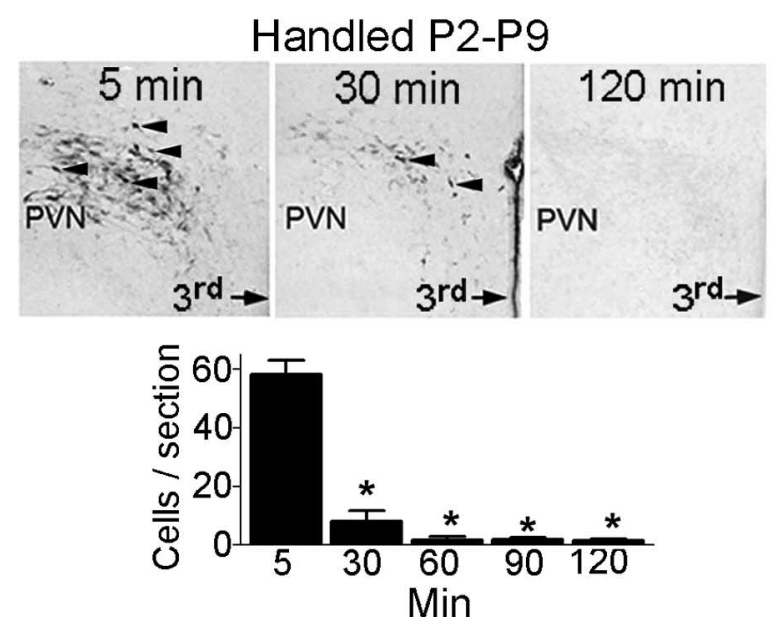

B
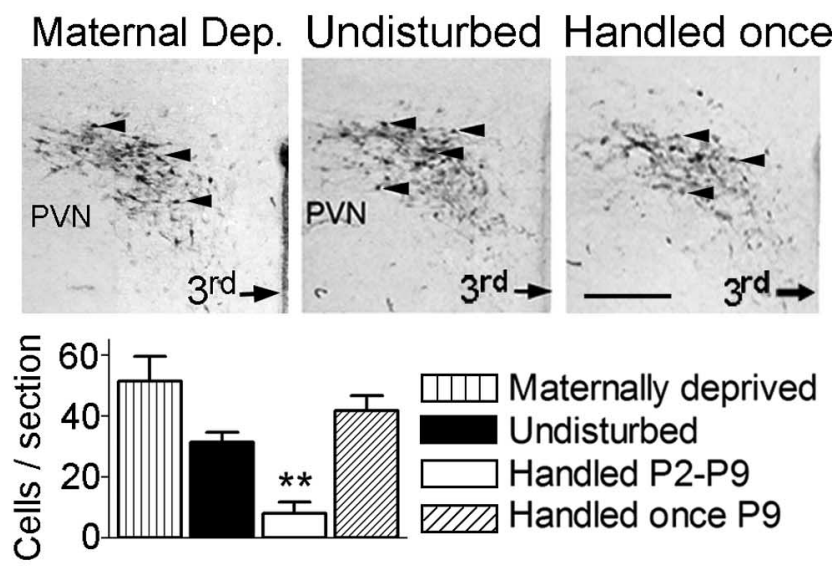

Figure 6. pERK is significantly dephosphorylated in PVN of pups handled recurrently but not in those handled once only. Neurons labeled for pERK (arrowheads) are depicted in bright-field photomicrographs of coronal sections at the level of PVN and quantified in the bar graphs below. $\boldsymbol{A}$, The number of pERK-positive cells was reduced fivefold in PVN of daily handled pups 30 min after their return to the dam on $\mathrm{P} 9$ and remained low for $2 \mathrm{~h}\left(F_{(4,8)}=60.66 ; p<0.001\right)$. $\boldsymbol{B}$, Handling once did not suffice to reduce the number of $\mathrm{pERK}$ cells in PVN when compared with daily handled rats (both groups at 30 min after return to the dam) and to maternally deprived and undisturbed controls. 3 rd, Third ventricle. ${ }^{*} p<0.001$, values differ statistically from those at the 5 min time point. ${ }^{* *} p<0.05$, values are significantly different from all other groups $\left(F_{(3,9)}=12.58\right)$. Scale bar, $500 \mu \mathrm{m} . n=2-4$ brains per time point.

Transcription of the CRH gene, measured as hnRNA expression, is modulated in recurrently handled rats Does downregulation of ERK phosphorylation lead to reduced transcription of the CRH gene? As shown in Figure 1, steady-state CRH mRNA levels were lower in PVN of recurrently handled rats. Here, we examined transcription of the CRH gene directly by comparing the production of unedited, CRH hnRNA in PVN of handled (from P2 to P8) and undisturbed (from P2 to P8) pups on P9. CRH hnRNA was measured before (basal) and at several time points after the onset of a 15 min separation from the dam (at 15, 45, and $75 \mathrm{~min}$ ). As shown in Figure 7, basal CRH hnRNA levels did not distinguish recurrently handled pups and those raised undisturbed ( $t$ test, $p>0.05$ ). It should be noted that these basal CRH hnRNA levels were barely detectable, consistent with previous studies (Baram and Hatalski, 1998; Chen et al., 2001b). Induction of CRH transcription by the 15 min separation stress differed significantly between the handled and the undisturbed groups (Fig. $7 A$ ). In rats raised undisturbed, levels of $\mathrm{CRH}$ hnRNA increased within $15 \mathrm{~min}$, peaked at 30-45 min, and were still significantly elevated at $75 \mathrm{~min}$ after the onset of the separation stress $\left(F_{(5,21)}=17.14 ; p<0.005\right)$. In contrast, induction of $\mathrm{CRH}$ hnRNA levels in recurrently handled pups was attenuated, reached significance only at the $30 \mathrm{~min}$ time point, and dissipated by $75 \mathrm{~min}$. Thus, both the magnitude and duration of transcriptional induction of $\mathrm{CRH}$ in response to the separation stress were reduced already on P9 in recurrently handled rats.

\section{Discussion}

Our principal findings are as follows. (1) Neuroplasticity of CRH gene expression, leading to chronic reduction of neuroendocrine stress responses, requires recurrent early-life handling. (2) Signaling cascades initiated by handling commence with transient, coordinate activation of specific neuronal populations at the time the pups return to the cage and receive a burst of sensory input (maternal care). (3) A single burst of this sensory input suffices to activate Fos within stress-modulatory regions, including ACe and BnST but not in PVT. (4) PVT activation requires recurrent handling and is associated with reduced transcription-factor activation in PVN. (5) The signaling cascade evoked by recurrent han- dling culminates in attenuated $\mathrm{CRH}$ gene transcription in response to subsequent stress. Together, these studies provide a neurobiological foundation for the profound neuroplasticity of stress-related genes evoked by early-life experience.

Early-life experience evokes enduring changes in expression levels of CRH and other stress-related genes

Early-life experience permanently alters expression levels of genes governing behavioral and neurohormonal stress responses (Avishai-Eliner et al., 2002). Thus, daily handling of rat pups reduces CRH expression levels in PVN and increases hippocampal GR expression. This experience-evoked neuroplasticity impacts hippocampal neuronal integrity (Meaney et al., 1988; Bredy et al., 2003) and learning/memory functions later in life (Huot et al., 2002; Brunson et al., 2005) and attenuates the magnitude of hormonal and behavioral stress responses (Walker et al., 1991; Plotsky and Meaney, 1993; Meerlo et al., 1999; Avishai-Eliner et al., 2001; Sanchez et al., 2001; Fenoglio et al., 2005).

We found previously that effects of handling on hypothalamic $\mathrm{CRH}$ expression emerged already by $\mathrm{P} 9$. Here we demonstrated that $\mathrm{CRH}$ downregulation did not occur after a single handling maneuver but required 1 week of daily handling. We then addressed the putative neuronal pathways and cellular mechanisms for this finding. We took advantage of the important discovery that "neuroplasticity" (Levine, 2000; Baram, 2003) or "reprogramming" (Weaver et al., 2001) evoked by handling depended on augmented maternal care (Denenberg and Whimby, 1963; Liu et al., 1997; Huot et al., 2004). Confirming that maternal licking/ grooming increased significantly on the pups' return to the dam, particularly during the initial $30 \mathrm{~min}$, we focused on this period to investigate the means by which this burst of maternal care initiated persistent changes in $\mathrm{CRH}$ expression.

Neuronal populations along a stress-modulating pathway are coordinately activated when handled pups return to their cages

To investigate mechanisms for the effects of handling-evoked sensory input on PVN-CRH expression, we first examined Fos- 
A

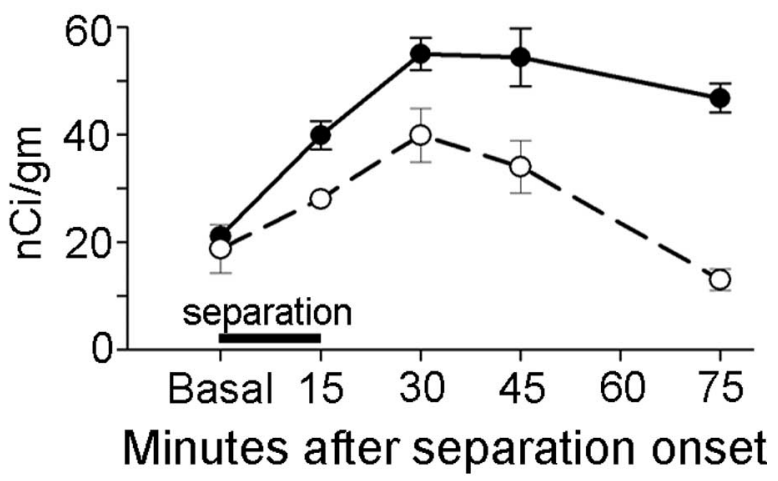

B

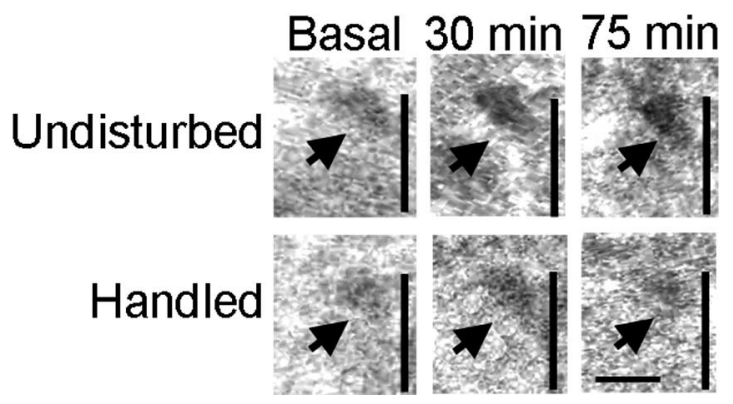

Figure 7. CRH hnRNA production in response to a separation stress is attenuated in PVN of pups handled recurrently compared with undisturbed controls. Quantification $(\boldsymbol{A})$ and autoradiograms $(\boldsymbol{B})$ of CRH hnRNA signal in PVN of daily handled (from P2 to P8) and of undisturbed P9 pups are shown. On P9, both groups were subjected to the handling procedure (i.e., were separated from the dam for $15 \mathrm{~min}$ and then returned to the dam). (RH hnRNA was measured at the onset of this separation (Basal), at the moment of the pups' return (15 min from separation onset), as well as at 45 and 75 min after the onset of separation from the mother (i.e., 30 and 60 min, respectively, after the pups' return to the dam). (RH hnRNA levels at the onset of the stress (indicated as "separation") did not differ between handled and undisturbed pups. Levels of CRH hnRNA were lower in recurrently handled rats (white circles) at 15, 30, 45, and $75 \mathrm{~min}$ after stress onset compared with undisturbed controls (black circles) (paired $t$ test, $p<0.05 ; R^{2}=$ 0.72). Because of the kinetics of CRH hnRNA production and decay (Kovacs and Sawchenko, 1996; Baram and Hatalski, 1998; (hen et al., 2001b), the 15 min time point probably reflects the effect of the separation, whereas the other time points are probably influenced by both separation and return of the pups to the dam. Levels of CRH hnRNA in handled pups reached significance only at $30 \min \left(F_{(5,12)}=6.48 ; p<0.005\right) . n=3-7$ brains per time point. In the bright-field photomicrographs, arrows point to the PVN. Vertical bar denotes the third ventricle. Scale bar, $500 \mu \mathrm{m}$.

induction patterns at several time points after handled pups returned to the dam, focusing on regions contributing to neuronal connections from sensory input to PVN (little consistent Fos induction occurred elsewhere). These structures include PVT, ACe, and BnST (supplemental Fig. 1, available at www.jneurosci. org as supplemental material), whose efferents influence hypothalamic CRH expression and/or release (Herman et al., 2003). $\mathrm{ACe}$ is generally considered to facilitate activation of stressresponsive, CRH-expressing PVN neurons (Beaulieu et al., 1989; Prewitt and Herman, 1994), and BnST subregions exert excitatory or inhibitory effects on PVN-mediated stress responses (Herman et al., 1994). Fos expression in PVT, ACe, and BnST was virtually nil in undisturbed or maternally deprived pups, but significant numbers of Fos-immunopositive neurons were present in recurrently handled $\mathrm{P} 9$ rats. The time course of Fos expression, peaking 30-90 min and over by $120 \mathrm{~min}$ after the pups' return to the cage, supports the notion that the burst of maternal stim- ulation elicited this coordinate activation of PVT, ACe, and BnST neurons.

Fos induction in PVT requires recurrent handling

On the last day of the week-long recurrent handling procedure, Fos expression was apparent in PVT, ACe, and BnST, all stressmodulating structures that define a pathway from sensory regions to the PVN (supplemental Fig. 1, available at www.jneurosci. org as supplemental material). In contrast, a single burst of maternal sensory stimulation (evoked by handling once only) induced Fos expression in ACe and BnST but not PVT. Thus, unlike ACe and BnST, Fos induction in PVT required recurrent handling. These findings are consistent with studies in adult rats, showing that Fos cells were more abundant in PVT of rats after exposure to recurrent stress compared with those stressed once (Bhatnagar and Dallman, 1998). These authors concluded that the recurrence-dependent activation of PVT implies that this region somehow stores memories of previous (stress-related) experiences.

PVT intercommunicates with ACe and other stressintegrating regions, including monosynaptic connections to PVN (Van der Werf et al., 2002). In addition, functional evidence for inhibitory influence of the PVT over ACe exists (Herman et al., 2003; Spencer et al., 2004). ACe and BnST facilitate CRH expression in PVN (Beaulieu et al., 1989; Feldman et al., 1994; Herman et al., 1994; Prewitt and Herman, 1994; Palkovits et al., 1998), so that the predicted net effect of PVT activation is inhibition of CRH-expressing neurons in PVN. Lesion and pharmacological experiments further support the role of PVT in suppressing HPA responses to recurrent stress (Bhatnagar and Dallman, 1998; Bhatnagar et al., 2002). Thus, PVT may relay inhibitory input to PVN to attenuate CRH-mediated, neuroendocrine responses to subsequent stresses (Ma and Lightman, 1998). Here, activation of PVT occurred only after recurrent handling, implying that activity patterns ("output") of PVT neurons will be augmented after recurrent compared with single handling and potentially convey memories of previous handling to $\mathrm{CRH}$ expressing neurons in PVN.

The nature of plasticity of PVT neuronal function after recurrent handling is unclear. Potential enhanced synaptic efficacy of PVT afferents to ACe or BnST should augment negative input to $\mathrm{CRH}$-expressing neurons in PVN. Alternatively, reduction of neurotransmitter release or synaptic efficacy of putative glutamatergic PVT-origin neurons innervating PVN directly may occur. This possibility is particularly intriguing in view of recent demonstration of structural plasticity of synaptic innervation in PVN (Horvath, 2005). Altered expression/function of stress-activated neuromodulators within PVT, including $\mathrm{CRH}$ receptor type II, may provide additional mechanisms for altering PVT neuronal output because this receptor is regulated by separation and stress in neonatal rat (Eghbal-Ahmadi et al., 1999). A change in the expression set point of this receptor (or other candidate mediators) would explain the longevity of these PVT changes.

\section{Fos induction in PVT is associated with reduced phosphorylation of ERK in PVN}

Fos induction in PVT was associated with reduced pERK in PVN of rats handled recurrently. ERK is a signaling molecule upstream of CRH transcription: with less pERK-dependent phosphorylation of CRE-binding transcription factors, fewer CRE-containing genes, e.g., CRH, are transcribed. Indeed, transcription of $\mathrm{CRH}$ gene in response to separation stress decreased in PVN of recurrently handled pups, in both magnitude and duration. These data 
indicate reduced sensitivity ("tone") of the molecular systems involved in stress responses. Over time, reduced transcription of $\mathrm{CRH}$ in response to recurrent stresses should yield reduced steady-state mRNA levels (other factors being equal), as observed in handled rats throughout their lives. In addition, reduced PVN-CRH levels attenuate ACTH and corticosterone release after subsequent stress (De Kloet et al., 1998; Avishai-Eliner et al., 2001), as found in handled rats already at P23 (Avishai-Eliner et al., 2001). Lower corticosterone levels promote expression of hippocampal GR (Reul and de Kloet, 1985; Kalinyak et al., 1987; Freeman et al., 2004) and an efficient shut-off of hormonal stress responses, yielding the phenotype of attenuated HPA axis function typical of adult rats handled early in life (Plotsky and Meaney, 1993; Fenoglio et al., 2005).

In summary, the current study delineates pathways and mechanisms by which recurrent handling, and consequent augmented maternal care, provoke neuroplasticity of neuronal systems governing stress responses. We define coordinate activation of stressregulatory structures and demonstrate the need for recurrent handling for recruitment of PVT into the pathway that eventually influences PVN-CRH expression. This may occur by (1) strengthening PVT synaptic connections that inhibit the facilitative signals from ACe and BnST to PVN at a critical developmental period (Baram et al., 1997) leading to enduringly lower expression, (2) reducing efficacy of excitatory PVT-PVN pathways, (3) modulating responsiveness of PVT to additional stress, perhaps via altered expression of CRF receptors type 2 within PVT, and (4) concerted interaction among these and other, unelucidated mechanisms that underlie these long-lasting effects of early-life experience on hypothalamic gene expression.

\section{References}

Avishai-Eliner S, Yi SJ, Newth CL, Baram TZ (1995) Effects of maternal and sibling deprivation on basal and stress-induced HPA components in the infant rat. Neurosci Lett 192:49-92.

Avishai-Eliner S, Eghbal-Ahmadi M, Tabatchnik E, Brunson KL, Baram TZ (2001) Downregulation of hypothalamic corticotropin-releasing hormone messenger ribonucleic acid precedes early-life hippocampal glucocorticoid receptor-mRNA changes. Endocrinology 142:89-97.

Avishai-Eliner S, Brunson KL, Sandman CA, Baram TZ (2002) Stressed out? Or in (utero). Trends Neurosci 25:518-524.

Baram TZ (2003) Long-term neuroplasticity and functional consequences of single versus recurrent early-life seizures. Ann Neurol 54:701-705.

Baram TZ, Hatalski CG (1998) Neuropeptide-mediated excitability: a key triggering mechanism for seizure generation in the developing brain. Trends Neurosci 21:471-476.

Baram TZ, Yi SJ, Avishai-Eliner S, Schultz L (1997) Developmental neurobiology of the stress-response: multi-level regulation of corticotropin releasing hormone function. Ann NY Acad Sci 814:252-256.

Beaulieu S, Pelletier G, Vaudry H, Barden N (1989) Influence of the central nucleus of the amygdala on the content of corticotropin-releasing factor in the median eminence. Neuroendocrinology 49:255-261.

Bender R, Lauterborn J, Gall CM, Cariaga W, Baram TZ (2001) Enhanced CREB phosphorylation in immature dentate gyrus granule cells indicates a specific role for CREB in granule cell differentiation. Eur J Neurosci 13:679-686.

Bhatnagar S, Dallman M (1998) Neuroanatomical basis for facilitation of hypothalamic-pituitary-adrenal responses to a novel stressor after chronic stress. Neuroscience 84:1025-1039.

Bhatnagar S, Viau V, Chu A, Soriano L, Meijer OC, Dallman MF (2000) A cholecystokinin-mediated pathway to the paraventricular thalamus is recruited in chronically stressed rats and regulates hypothalamic-pituitaryadrenal function. J Neurosci 20:5564-5573.

Bhatnagar S, Huber R, Nowak N, Trotter P (2002) Lesions of the posterior paraventricular thalamus block habituation of hypothalamic-pituitaryadrenal responses to repeated restraint. J Neuroendocrinol 14:403-410.

Bisler S, Schleicher A, Gass P, Stehle JH, Zilles K, Staiger JF (2002) Expression of c-Fos, ICER, Krox-24 and JunB in the whisker-to-barrel pathway of rats: time course of induction upon whisker stimulation by tactile exploration of an enriched environment. J Chem Neuroanat 23:187-198.

Bredy TW, Humpartzoomian RA, Cain DP, Meaney MJ (2003) Partial reversal of the effect of maternal care on cognitive function through environmental enrichment. Neuroscience 118:571-576.

Brown CP, Smotherman WP, Levine S (1977) Interaction-induced reduction in differential maternal responsiveness: an effect of cue-reduction or behavior? Dev Psychobiol 10:273-280.

Brunson KL, Eghbal-Ahmadi M, Bender R, Chen Y, Baram TZ (2001) Longterm, progressive hippocampal cell loss and dysfunction induced by early-life administration of corticotropin-releasing hormone reproduce the effects of early-life stress. Proc Natl Acad Sci USA 98:8856-8861.

Brunson KL, Kramar E, Lin B, Chen Y, Colgin LL, Yanagihara TK, Lynch G, Baram TZ (2005) Mechanisms of late-onset cognitive decline after early-life stress. J Neurosci 25:9328-9338.

Caba M, Rovirosa MJ, Silver R (2003) Suckling and genital stroking induces Fos expression in hypothalamic oxytocinergic neurons of rabbit pups. Brain Res Dev Brain Res 143:119-128.

Caldji C, Tannenbaum B, Sharma S, Francis D, Plotsky PM, Meaney MJ (1998) Maternal care during infancy regulates the development of neural systems mediating the expression of fearfulness in the rat. Proc Natl Acad Sci USA 95:5335-5340.

Chen Y, Brunson K, Müller MB, Cariaga W, Baram TZ (2000) Immunocytochemical distribution of corticotropin-releasing hormone receptor type-1 $\left(\mathrm{CRF}_{1}\right)$-like immunoreactivity in the mouse brain: light microscopy analysis using an antibody directed against the C-terminus. J Comp Neurol 420:305-323.

Chen Y, Bender R, Frotscher M, Baram TZ (2001a) Novel and transient populations of corticotropin-releasing hormone-expressing neurons in developing hippocampus suggest unique functional roles: a quantitative spatiotemporal analysis. J Neurosci 21:7171-7181.

Chen Y, Hatalski CG, Brunson KL, Baram TZ (2001b) Rapid phosphorylation of the CRE binding protein precedes stress-induced activation of the corticotropin releasing hormone gene in medial parvocellular hypothalamic neurons of the immature rat. Mol Brain Res 96:39-49.

Chen Y, Bender RA, Brunson KL, Pomper JK, Grigoriadis DE, Wurst W, Baram TZ (2004) Modulation of dendritic differentiation by corticotropin-releasing factor in the developing hippocampus. Proc Natl Acad Sci USA 101:15782-15787.

Coolen LM, Peters HJ, Veening JG (1997) Distribution of Fos immunoreactivity following mating versus anogenital investigation in the male rat brain. Neuroscience 77:1151-1161.

De Kloet ER, Vreugdenhil E, Oitzl MS, Joels M (1998) Brain corticosteroid receptor balance in health and disease. Endocr Rev 19:269-301.

Denenberg VH, Whimby AE (1963) Behav of adult rats is modified by the experiences their mothers had as infants. Science 142:1192-1193.

Dent GW, Smith MA, Levine S (2000) Rapid induction of corticotropinreleasing hormone gene transcription in the paraventricular nucleus of the developing rat. Endocrinology 141:1593-1598.

Dube C, Brunson K, Nehlig A, Baram TZ (2000) Activation of specific neuronal circuits by corticotropin releasing hormone, as indicated by c-fos expression and glucose metabolism. J Cereb Blood Flow Metab 20:1414-1424

Eghbal-Ahmadi M, Avishai-Eliner S, Hatalski CG, Baram TZ (1999) Differential regulation of the expression of corticotropin-releasing factor receptor type $2\left(\mathrm{CRF}_{2}\right)$ in hypothalamus and amygdala of the immature rat by sensory input and food intake. J Neurosci 19:3982-3991.

Feldman S, Conforti N, Itzik A, Weidenfeld J (1994) Differential effect of amygdaloid lesions on CRF-41, ACTH and corticosterone responses following neural stimuli. Brain Res 658:21-26.

Fenoglio KA, Brunson KL, Avishai-Eliner S, Chen Y, Baram TZ (2004) Region-specific onset of handling-induced changes in corticotropinreleasing factor and glucocorticoid receptor expression. Endocrinology 145:2702-2706.

Fenoglio KA, Brunson KL, Avishai-Eliner S, Stone BA, Kapadia BJ, Baram TZ (2005) Enduring, handling-evoked enhancement of hippocampal memory function and glucocorticoid receptor expression involves activation of the corticotropin-releasing factor type 1 receptor. Endocrinology 146:4090-4096.

Francis DD, Champagne FA, Liu D, Meaney MJ (1999) Maternal care, gene expression, and the development of individual differences in stress reactivity. Ann NY Acad Sci 896:66-84. 
Freeman AI, Munn HL, Lyons V, Dammermann A, Seckl JR, Chapman KE (2004) Glucocorticoid down-regulation of rat glucocorticoid receptor does not involve differential promoter regulation. J Endocrinol 183:365-374.

Hatalski CG, Brunson KL, Tantayanubutr B, Chen Y, Baram TZ (2000) Neuronal activity and stress differentially regulate hippocampal and hypothalamic corticotropin-releasing hormone expression in the immature rat. Neuroscience 101:571-580.

Herman JP, Cullinan WE, Watson SJ (1994) Involvement of the bed nucleus of the stria terminalis in tonic regulation of paraventricular hypothalamic CRH and AVP mRNA expression. J Neuroendocrinol 6:433-442.

Herman JP, Figueiredo H, Mueller NK, Ulrich-Lai Y, Ostrander MM, Choi DC, Cullinan WE (2003) Central mechanisms of stress integration: hierarchical circuitry controlling hypothalamo-pituitary-adrenocortical responsiveness. Front Neuroendocrinol 24:151-180.

Horvath TL (2005) The hardship of obesity: a soft-wired hypothalamus. Nat Neurosci 8:561-565.

Huot RL, Plotsky PM, Lenox RH, McNamara RK (2002) Neonatal maternal separation reduces hippocampal mossy fiber density in adult Long Evans rats. Brain Res 950:52-63.

Huot RL, Gonzalez ME, Ladd CO, Thrivikraman KV, Plotsky PM (2004) Foster litters prevent hypothalamic-pituitary-adrenal axis sensitization mediated by neonatal maternal separation. Psychoneuroendocrinology 29:279-289.

Ju G, Swanson LW, Simerly RB (1989) Studies on the cellular architecture of the bed nuclei of the stria terminalis in the rat. II. Chemoarchitecture. J Comp Neurol 280:603-621.

Kalinyak JE, Dorin RI, Hoffman AR, Perlman AJ (1987) Tissue-specific regulation of glucocorticoid receptor mRNA by dexamethasone. J Biol Chem 262:10441-10444.

Kovacs KJ, Sawchenko PE (1996) Sequence of stress-induced alterations in indices of synaptic and transcriptional activation in parvocellular neurosecretory neurons. J Neurosci 16:262-273.

Labiner DM, Butler LS, Cao Z, Hosford DA, Shin C, McNamara JO (1993) Induction of c-fos mRNA by kindled seizures: complex relationship with neuronal burst firing. J Neurosci 13:744-751.

Levine S (1957) Infantile experience and resistance to physiological stress. Science 126:405.

Levine S (1967) Maternal and environmental influences on the adrenocortical response to stress in weanling rats. Science 156:258-260.

Levine S (2000) Influence of psychological variables on the activity of the hypothalamic-pituitary-adrenal axis. Eur J Pharmacol 405:149-160.

Liu D, Diorio J, Tannenbaum B, Caldji C, Francis D, Freedman A, Sharma S, Pearson D, Plotsky PM, Meaney MJ (1997) Maternal care, hippocampal glucocorticoid receptors, and hypothalamic-pituitary-adrenal response to stress. Science 277:1659-1662.

Ma XM, Lightman SL (1998) The arginine vasopressin and corticotrophinreleasing hormone gene transcription responses to varied frequencies of repeated stress in rats. J Physiol (Lond) 510:605-614.

Martinez M, Calvo-Torrent A, Herbert J (2002) Mapping brain response to social stress in rodents with c-fos expression. Stress 5:3-13.

Meaney MJ, Aitken DH, van Berkel C, Bhatnagar S, Sapolsky RM (1988) Effect of neonatal handling on age-related impairments associated with the hippocampus. Science 239:766-768.

Meerlo P, Horvath KM, Nagy GM, Bohus B, Koolhaas JM (1999) The influence of postnatal handling on adult neuroendocrine and behavioural stress reactivity. J Neuroendocrinol 11:925-933.

Palkovits M, Young III WS, Kovacs K, Toth Z, Makara GB (1998) Alterations in corticotropin-releasing hormone gene expression of central amygdaloid neurons following long-term paraventricular lesions and adrenalectomy. Neuroscience 85:135-147.
Paxinos G, Watson C (1982) The rat brain in stereotaxic coordinates. Sydney: Academic.

Peng Z, Houser CR (2005) Temporal patterns of Fos expression in the dentate gyrus after spontaneous seizures in a mouse model of temporal lobe epilepsy. J Neurosci 25:7210-7220.

Plotsky PM, Meaney MJ (1993) Early, postnatal experience alters hypothalamic corticotropin-releasing factor (CRF) mRNA, median eminence CRF content and stress-induced release in adult rats. Mol Brain Res 18:195-200.

Plotsky PM, Thrivikraman KV, Nemeroff CB, Caldji C, Sharma S, Meaney MJ (2005) Long-term consequences of neonatal rearing on central corticotropin-releasing factor systems in adult male rat offspring. Neuropsychopharmacology 30:2192-2204.

Prewitt CM, Herman JP (1994) Lesion of the central nucleus of the amygdala decreases basal CRH mRNA expression and stress-induced ACTH release. Ann NY Acad Sci 746:438-440.

Reul JM, de Kloet ER (1985) Two receptor systems for corticosterone in rat brain: microdistribution and differential occupation. Endocrinology 117:2505-2511.

Sanchez MM, Ladd CO, Plotsky PM (2001) Early adverse experience as a developmental risk factor for later psychopathology: evidence from rodent and primate models. Dev Psychopathol 13:419-449.

Seasholtz AF, Thompson RC, Douglass JO (1988) Identification of a cyclic adenosine monophosphate-responsive element in the rat corticotropinreleasing hormone gene. Mol Endocrinol 2:1311-1319.

Sherwood NM, Timiras PS (1970) A stereotaxic atlas of the developing rat brain. Berkeley, CA: University of California.

Spencer SJ, Fox JC, Day TA (2004) Thalamic paraventricular nucleus lesions facilitate central amygdala neuronal responses to acute psychological stress. Brain Res 997:234-237.

Van der Werf YD, Witter MP, Groenewegen HJ (2002) The intralaminar and midline nuclei of the thalamus. Anatomical and functional evidence for participation in processes of arousal and awareness. Brain Res Brain Res Rev 39:107-140.

van Oers HJ, de Kloet ER, Whelan T, Levine S (1998) Maternal deprivation effect on the infant's neural stress markers is reversed by tactile stimulation and feeding but not by suppressing corticosterone. J Neurosci 18:10171-10179.

van Oers HJ, de Kloet ER, Levine S (1999) Persistent effects of maternal deprivation on HPA regulation can be reversed by feeding and stroking, but not by dexamethasone. J Neuroendocrinol 11:581-588.

Walker CD, Scribner KA, Cascio CS, Dallman MF (1991) The pituitaryadrenocortical system of neonatal rats is responsive to stress throughout development in a time-dependent and stressor-specific fashion. Endocrinology 128:1385-1395.

Watts AG, Tanimura S, Sanchez-Watts G (2004) Corticotropin-releasing hormone and arginine vasopressin gene transcription in the hypothalamic paraventricular nucleus of unstressed rats: daily rhythms and their interactions with corticosterone. Endocrinology 145:529-540.

Weaver IC, La Plante P, Weaver S, Parent A, Sharma S, Diorio J, Chapman KE, Seckl JR, Szyf M, Meaney MJ (2001) Early environmental regulation of hippocampal glucocorticoid receptor gene expression: characterization of intracellular mediators and potential genomic target sites. Mol Cell Endocrinol 185:205-218.

West AE, Griffith EC, Greenberg ME (2002) Regulation of transcription factors by neuronal activity. Nat Rev Neurosci 3:921-931.

Yi SJ, Baram TZ (1994) Corticotropin releasing factor mediates the response to cold stress in the neonatal rat, without compensatory enhancement of the peptide's gene expression. Endocrinology 135:2364-2368. 